\title{
Melanoma Cell Factory for Glycolipid Production
}

\author{
Maria Carmelita Z. Kasuya and Kenichi Hatanaka \\ Institute of Industrial Science, The University of Tokyo \\ Japan
}

\section{Introduction}

Glycolipids are ubiquitous in membranes of biological systems and play crucial roles in cell surface events including cell proliferation, differentiation, transmembrane signaling, cell-cell interactions, cell recognition, motility and cell - substrate interactions such as embryogenesis, inflammation and carcinogenesis (Hakomori, 1981; Kolter, 2002; Varki, 1999). Glycolipids, particularly gangliosides, mediate cell adhesion and modulate signal transduction. Gangliosides, cell surface glycolipids with at least one sialic acid residue, are located at the outer cell-surface of plasma membranes (Gervay et al., 1993). They are found predominantly in the nervous system where they constitute about $10 \%$ of all phospholipids. Gangliosides have also been detected in the liver of several species of shark, rat kidney, cerebelum of chicken, mouse erythrocytes, human brain and in human melanoma tumors (Li, 2002; Ozawa, 1993; Saito, 1982).

Gangliosides are involved in several diseases such as Tay-Sachs disease and Guillan-Barré syndrome. Impaired ganglioside metabolism is also relevant to Alzheimer's disease. Gangliosides bind specifically to virus such as influenza virus and various toxins such as tetanus, cholera and botulinum (Prichet \& Paulson, 1989; Sun, 2000; Suzuki, 1990). Gangliosides are also implicated in skin cancer. Human melanoma cells overexpress ganglioside (Freeze et al., 1993). Normal melanocytes predominantly express GM3 (greater than 90\%) and GD3 (less than 5\%) (Hoon 1988, 1992). However, malignant melanoma expresses other types of gangliosides including GM2 and GD2. Human melanoma cells express the four major gangliosides (GM3, GD3, GM2 and GD2).

Considering the essential roles played by glycolipids in biochemical and cellular processes, development of methods for their rapid and efficient synthesis is necessary. Isolation from natural sources affords glycolipids but with very limited amounts. The conventional chemical synthetic approach gives glycolipids with high purity in good yield. However, the poor stereoselectivity and the multi-step operation involving tedious protection and deprotection schemes are among the many shortcomings. Enzyme synthesis promises high levels of regioselectivity and stereoselectivity but the availability and high cost have to be reckoned with.

As part of our continued interest in the synthesis of glycolipids, the saccharide primer strategy was employed as a viable alternative to existing methods (Kasuya, 2000, 2004, 2005, 2007, 2010a, 2010b, 2010c, 2010d; Sato, 2007). The saccharide primer method using animal cells and amphiphilic glycoside primers such dodecyl $\alpha$ - and $\beta$-lactoside, 12 - and 2-azidododecyl 
lactosides, dodecyl $\alpha$ - and $\beta$-galactoside, dodecyl $\alpha$ - and $\beta$-glucoside, thiolactosides, glycosides with perfluoroalkyl chains and fluorinated galactoside was developed for the fast, simple and convenient synthesis of glycolipids. The saccharide primers were chemically synthesized and introduced into mouse melanoma B16 cells to generate GM3- and GM4-type gangliosides in fairly good yield.

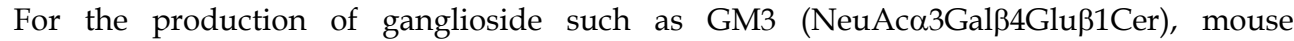
melanoma B16 cell is a good candidate to produce chemical quantities with homogeneity required for application since cancer cells proliferate even beyond confluency due to the absence of contact inhibition. Mouse melanoma B16 cells in culture could serve as the "cell factory" where the raw material (saccharide primer) is processed by endogenous donors and enzymes to generate products, biologically important glycolipids, with high stereo- and regioselectivity. By employing mouse melanoma B16 cells, production of desired ganglioside analogues, such as GM3 and GM4, via saccharide primer strategy is possible.

This chapter presents the versatiliy of melanoma B16 cells for the convenient production of glycolipids via saccharide primer strategy.

\section{Saccharide primer method}

The saccharide primer strategy (shown in figure 1) combines chemical synthetic methods with cellular biosynthetic processes for the synthesis of glycolipids. The basic building blocks, called saccharide primers, are synthetically accessible amphiphilic glycosides that resemble lactosyl ceramide, the intermediate in the biosynthetic pathway (Miura \& Yamagata, 1997). When introduced to cells, the lactosyl ceramide analogues with a single lipophilic chain serve as substrate for cellular-mediated glycosylation to afford oligosaccharide with glycan structures exactly the same as those produced by the cells used (Sarkar 1995, 1997, 2000). By using different types of cells, a library of biologically important glycolipids can be generated from one kind of saccharide primer.

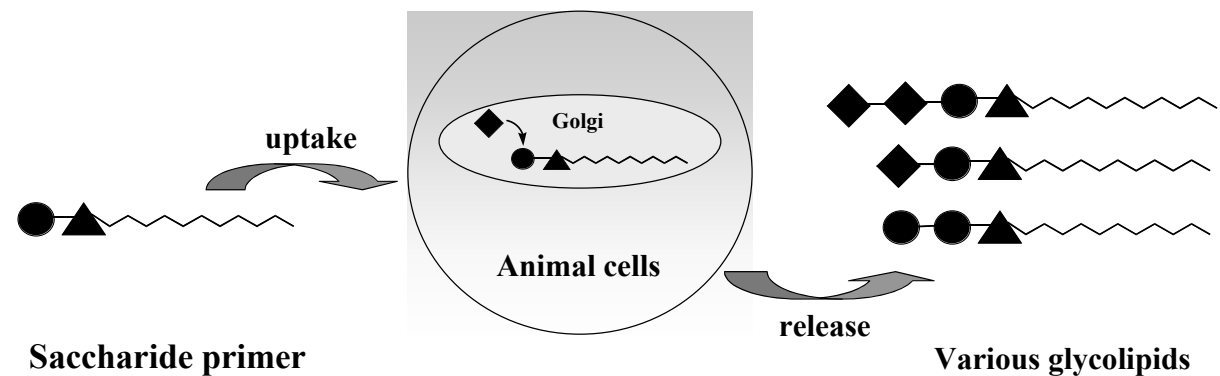

Saccharide chain elongation

Fig. 1. Saccharide primer strategy

The basic requirements for the saccharide primer method are the appropriate cell line and the amphiphilic saccharide primer. Cells are treasuries of glycosyltransferases and glycosyl donors. Careful choice of cells is important because the kind of cells employed will determine the structure of the products formed. For mass production, the cell must be amenable to continuous culture for several days. The amphiphilic saccharide primer, substrate for cellular mediated glycosylation, consists of a saccharide head (hydrophilic 
moiety) and an alkyl tail (hydrophobic moiety). It is accessible in a few steps through simple chemical synthesis. Generally, the saccharide primers can be prepared by conventional methods of glycosylation of an alcohol with a glycoside derivative followed by deacylation under Zemplen conditions.

The cellular uptake of primer and release of glycosylated products by cells depend on the hydrophobic (aglycon moiety) and hydrophilic (saccharide moiety) balance. The appropriate chain length of the aglycon moeity is an important consideration to ensure the efficient uptake by cells, glycosylation and release of products to the culture medium for collection. A short aglycon unit such as an octyl group does not allow incorporation of the primer into the cells. On the other hand, a long aglycon unit such as a stearyl group allows entry into cells but the products are not released into the culture medium. The dodecyl aglycon is the most appropriate length to ensure uptake, elongation and release of product as shown in figure 2 (Nakajima et al., 1998).

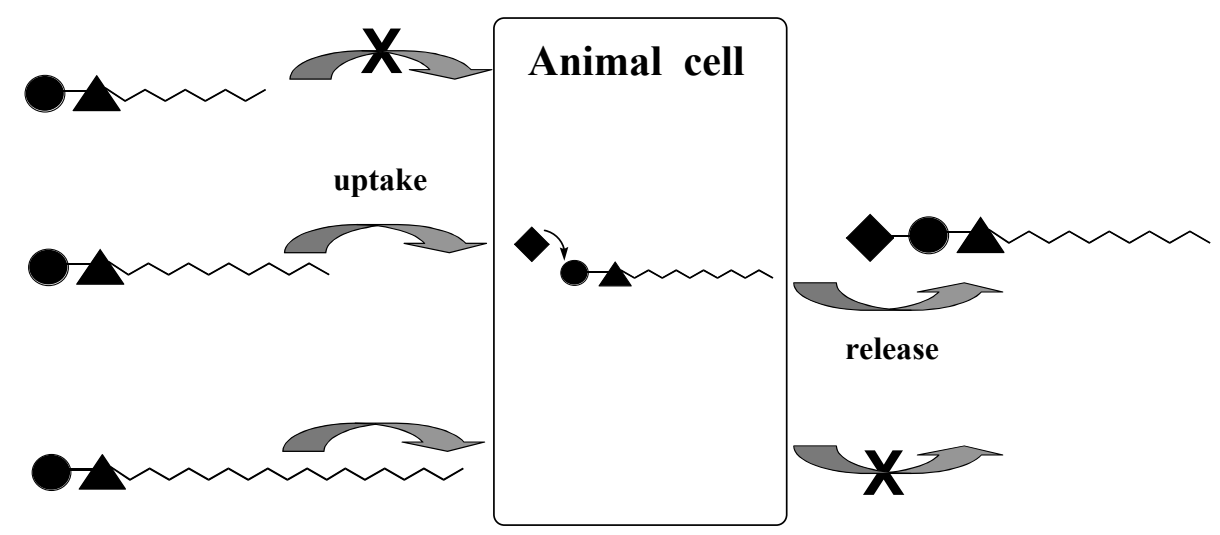

Fig. 2. Effect of alkyl chain length on saccharide primer uptake and release of product

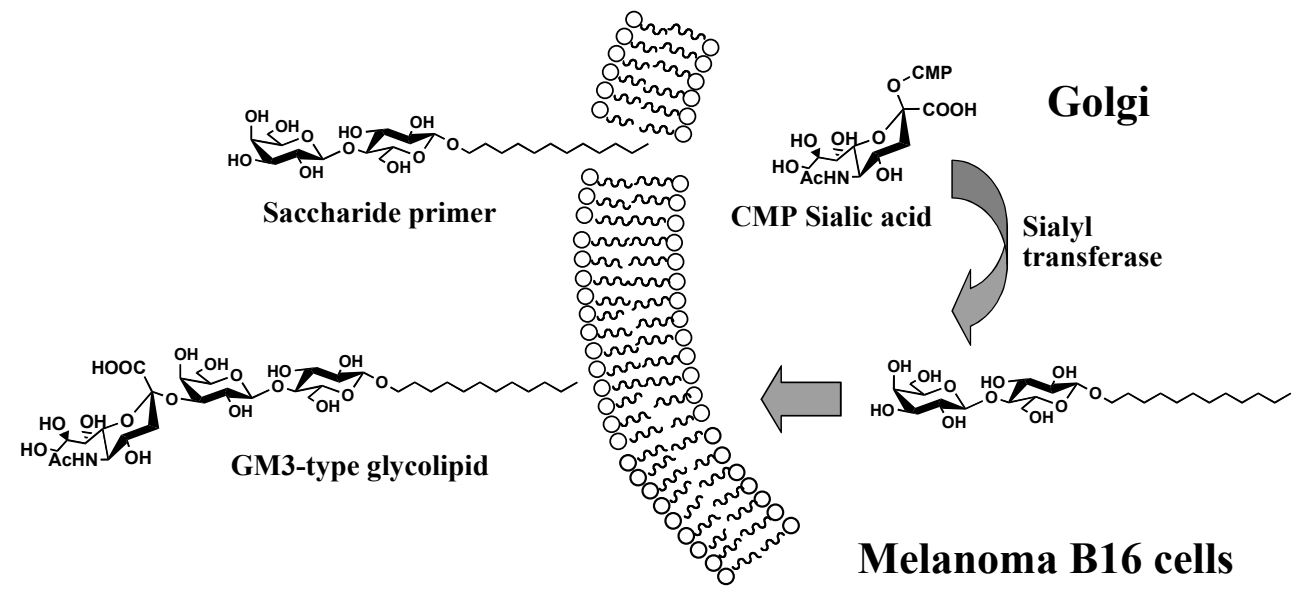

Fig. 3. Cellular enzyme-mediated glycosylation of saccharide primer 
For priming to occur, the saccharide primers must pass through the plasma membrane and enter the Golgi, where the glycosyltransferases reside and where glycosylation takes place (Kolter et al., 2002). After diffusion through the cell membrane, the saccharide primers are assimilated into the glycosphingolipid biosynthetic pathway and function as acceptor for the glycosyl transferases. The sugar nucleotide donor and the glycosyl transferase are both endogenously prepared by the cells. When administered into animal cells such as mouse melanoma B16 cells, a lactoside primer functions as acceptor for the GM3 synthase, $\alpha-(2 \rightarrow 3)$ sialyl transferase, resulting in sialylation of the terminal galactosyl residue of the lactosyl moiety to afford a GM3-type glycolipid as shown in figure 3.

\subsection{Methodology}

The important steps in glycolipid production using melanoma B16 cells via saccharide primer method include (1) chemical synthesis of saccharide primer, (2) administration, cellular uptake and glycosylation of saccharide primer, (3) lipid extraction, (4) analysis of products, and (5) structure elucidation of product (figure 4).
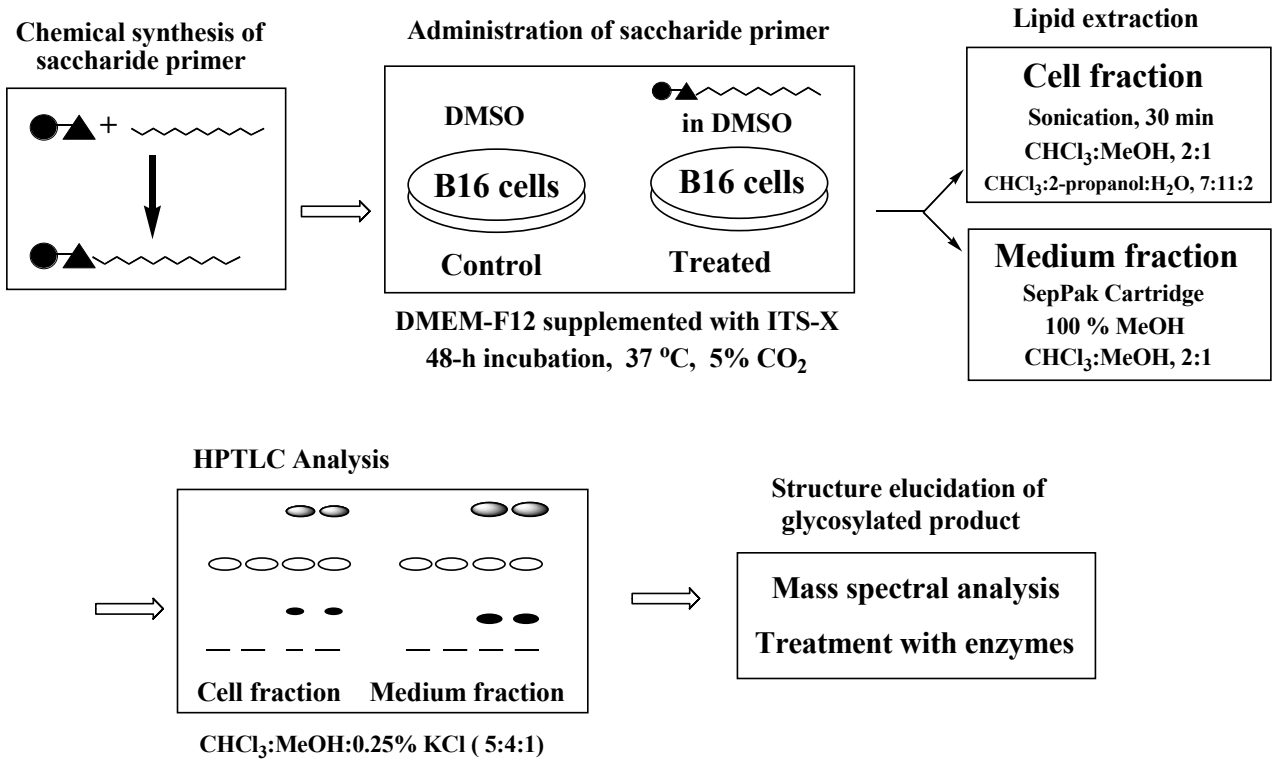

Fig. 4. General method for glycolipid production via saccharide primer strategy

\subsubsection{Chemical synthesis of saccharide primers}

Generally, the saccharide primers are prepared in 2 steps: glycosylation of an alcohol with a monosaccharide (peracetylated galactose or glucose) or a disaccharide (peracetylated lactose) derivative followed by deacylation. Glycosylation is carried out using Lewis acid such as $\mathrm{BF}_{3} \cdot \mathrm{OEt}_{2}$ as catalyst. The $\beta$-linked product is separated by column chromatography. Deacylation under Zemplen conditions using sodium methoxide and methanol affords the desired saccharide primers that could be purified by recrystallization using methanol. The structure of the saccharide primers is confirmed from the NMR and mass spectral results. A 
$50 \mathrm{mM}$ stock solution is prepared by dissolving the saccharide primer in sterile dimethylsulfoxide $\left(\mathrm{Me}_{2} \mathrm{SO}\right)$.

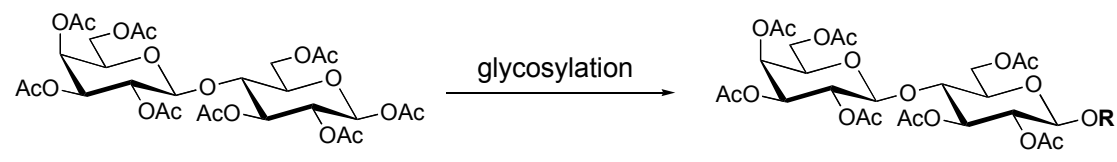

R: alkyl chain

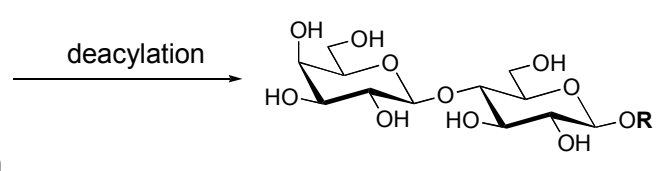

\subsubsection{Administration, cellular uptake and glycosylation}

Inocula of $2 \times 10^{6}$ of mouse melanoma B16 cells are cultured in 100-mm dishes containing $7 \mathrm{~mL}$ of 1:1 DMEM-F12 supplemented with $10 \%$ fetal bovine serum (FBS) and maintained in humidified atmosphere of $5 \% \mathrm{CO}_{2}$ air at $37^{\circ} \mathrm{C}$ for $48 \mathrm{~h}$. Then, cells are washed twice with medium supplemented with insulin-transferrin-selenium $X$ (ITS-X) solution to remove the serum, and then incubated with $50 \mu \mathrm{M}$ of the saccharide primer for $48 \mathrm{~h}$ at $37^{\circ} \mathrm{C}$. During incubation of cells in the presence of primer, uptake and subsequent elongation by cellular enzymes take place to afford products that are released to the culture medium.

\subsubsection{Extraction of lipids and structure elucidation of product}

After incubation in the presence of primer, the culture media and cells are collected. The lipids are extracted from the cell pellet with $\mathrm{CHCl}_{3}: \mathrm{MeOH}(2: 1, \mathrm{v} / \mathrm{v})$, then with $\mathrm{CHCl}_{3}:$ 2-propanol : water $(7: 11: 2, \mathrm{v} / \mathrm{v})$, in a sonicated bath. On the other hand, the lipids from the culture media are purified using SepPak C18 column. Lipids from the cell homogenate and culture medium fractions are analyzed by HPTLC with $\mathrm{CHCl}_{3}: \mathrm{MeOH}: 0.2 \%$ aq KCl $(5: 4: 1, \mathrm{v} / \mathrm{v})$ as developing solvent. HPTLC plates are sprayed with resorcinol (Svennerholm, 1957), then with orcinol- $\mathrm{H}_{2} \mathrm{SO}_{4}$ reagent, and heated $\left(120^{\circ} \mathrm{C}\right)$ to detect the products of glycosylation. The putative bands corresponding to glycosylated primers are scraped from HPTLC plate, extracted with methanol and analyzed. The structure of the product is elucidated from the results of mass spectral analysis and enzyme hydrolysis.

\section{Glycolipid production using various kinds of saccharide primers}

\subsection{Dodecyl glucoside, galactoside and lactoside primers}

The saccharide primers are analogues of lactosyl ceramide, the natural precursor for the biosynthesis of glycolipids. Although the hydrophilic moieties are the same, the saccharide primers have a single hydrophobic tail, a dodecyl aglycon unit. Preliminary work focused on $n$-dodecyl $\beta$-lactoside primer that is structurally, the closest analogue to the natural precursor (Miura \& Yamagata, 1997; Nakajima, 1998). $n$-Dodecyl $\beta$-lactoside primer does not have adverse effects on viability and morphology of melanoma B16 cells at an initial concentration of $50 \mu \mathrm{M}$. Cytotoxicity becomes prevalent at higher concentrations. Incubation of mouse melanoma B16 cells in the presence of dodecyl lactoside primer gave a GM3-type 
glycolipid (shown in Table 2) that was mostly found in the culture medium fraction. To determine whether primers with monosaccharide residue would have the same effect on B16 cells on glycolipid production, glucoside and galactoside primers with the same dodecyl aglycon unit were also prepared and administered into B16 cells (Kasuya et al., 2005).

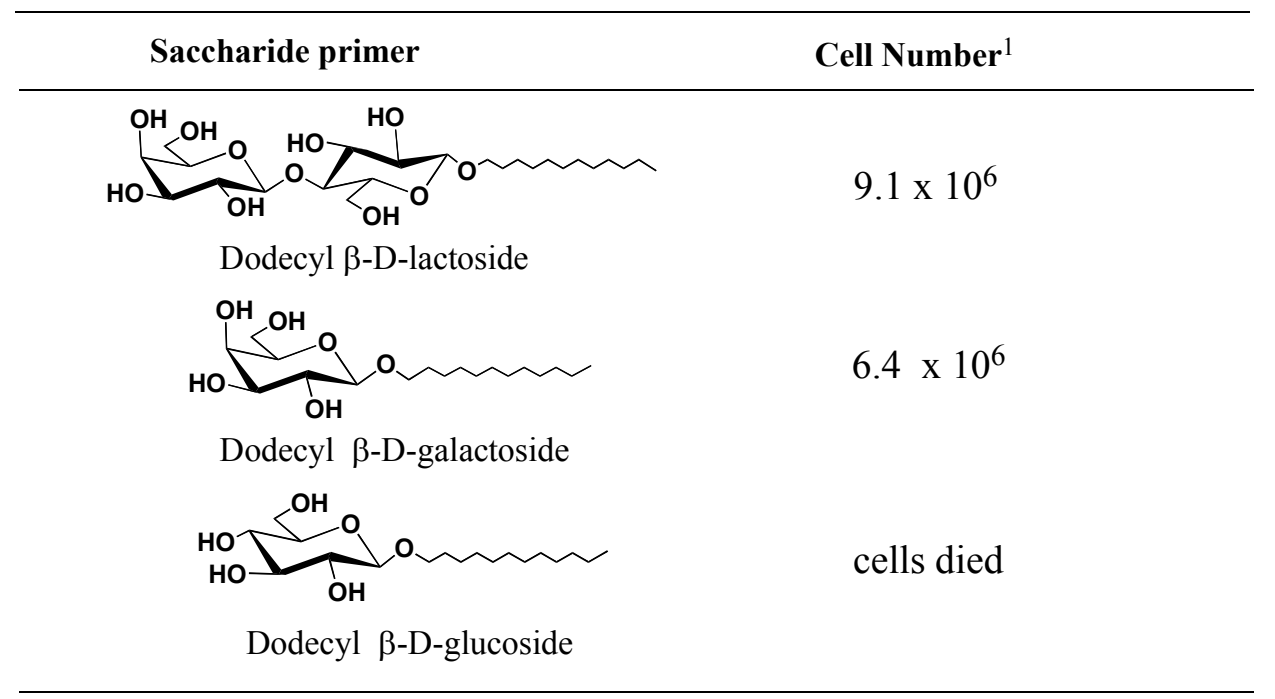

${ }^{1}$ Control: $10.8 \times 10^{6}$

Table 1. Cell number after 48-h incubation of cells with the saccharide primer.

As shown in table 1, the growth of melanoma B16 cells in the presence of $\beta$-lactoside was similar to that of control indicating that the lactoside primer does not express remarkable toxicity towards the cells at $50 \mu \mathrm{M}$ concentration. However, the monosaccharide primers exhibited cytotoxicity to a certain extent. Relative to control, dodecyl galactoside primer reduced the cell number by almost half while dodecyl glucoside primer was cytotoxic. Although the galactoside primer exhibited moderate cytotoxicty, the galactoside primer passed through the plasma membrane and was assimilated in the glycosphingolipid biosynthetic pathway to function as acceptor for $\alpha-(2 \rightarrow 3)$-sialyl transferase, resulting in the direct glycosylation occurring at the galactosyl residue to afford a GM4-type glycolipid as shown in Table 2. Expectedly, the $\beta$-glucoside primer that expressed cytotoxicity $(90 \%$ of the cells died) was not elongated.

\section{$3.2 \alpha$ - and $\beta$-linked saccharide primers}

Whether or not the glycosidic linkage of the aglycon unit of saccharide primers affects the production of glycolipids by melanoma B16 cells was also investigated. Dodecyl $\alpha$ - and $\beta$ - lactoside, dodecyl $\alpha$ - and $\beta$-galactoside, dodecyl $\alpha$ - and $\beta$-glucoside were chemically synthesized and introduced to mouse melanoma B16 cells (Kasuya et al., 2005).

The assimilation of primers into cells through the plasma membrane seemed to be unaffected by the anomeric linkage. Regardless of the $\alpha$ - or $\beta$-linkage to the aglycon unit, 


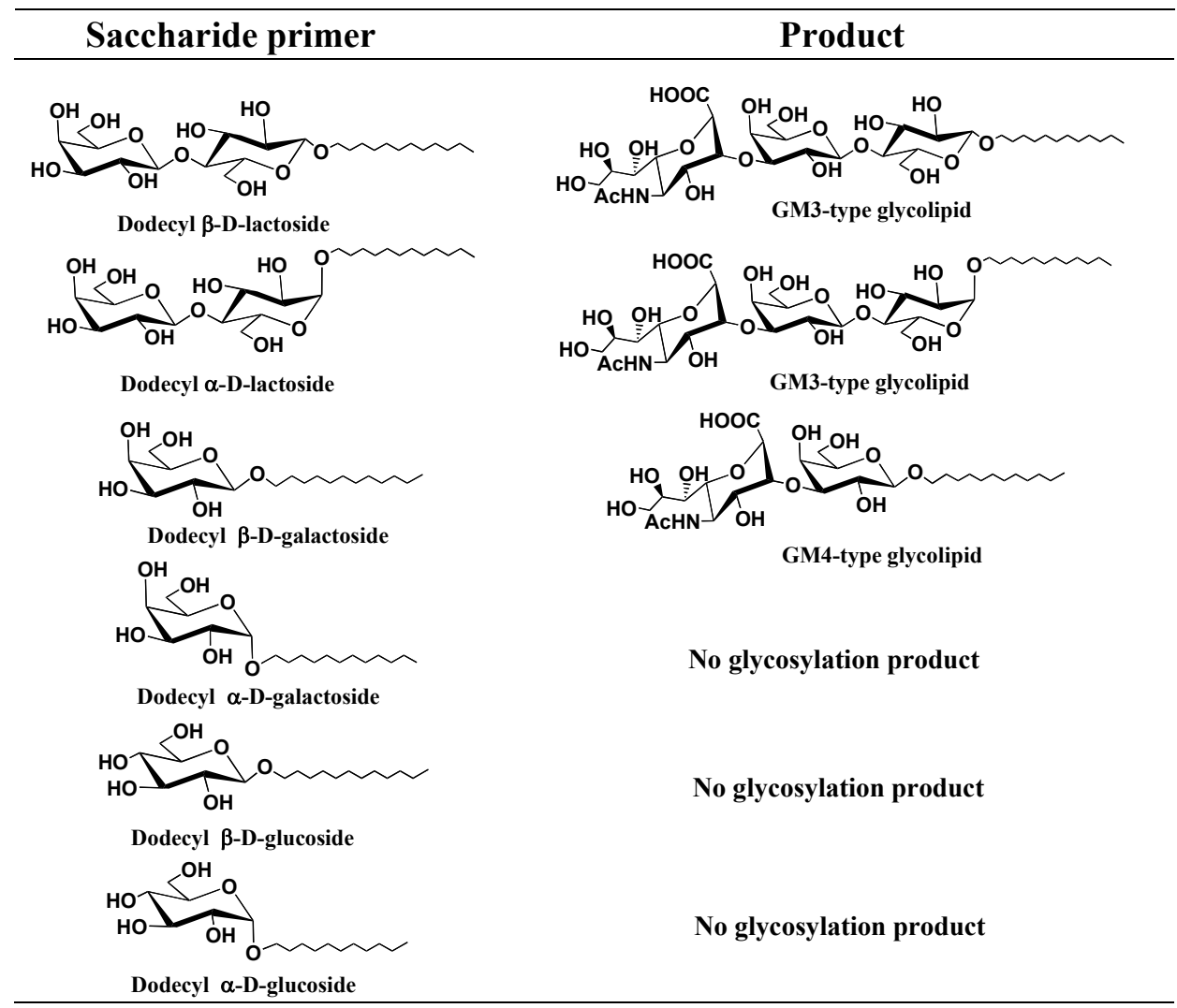

Table 2. Results after 48-h incubation of melanoma B16 cells with $50 \mu \mathrm{M} \alpha$ - or $\beta$ - linked saccharide primers.

melanoma B16 cells take in the primers. However, elongation occurred only with dodecyl $\alpha-$ and $\beta$-lactoside, and dodecyl $\beta$-galactoside primers to afford GM3- and GM4-type oligosaccharides, respectively as shown in Table 2 . In cellular sialylation, a terminal galactose residue that is $\beta$-linked to the adjacent saccharide or aglycon unit is necessary. Sialyltransferases reside in the Golgi compartment and transfer a sialic acid residue from CMP-sialic acid to the C-6 or C-3 hydroxyl group at the non-reducing Gal-, Gal NAc-, or GlcNAc residue. For glycosylation of primers by cells to occur, the glycoside must diffuse through the plasma membrane and enter the Golgi. The anomeric linkage of the aglycon unit seems irrelevant for primer incorporation into melanoma B16 cells. However, the anomeric $\beta$-linkage of the terminal galactoside residue that is the site for sialylation of the primers is significant for elongation.

\subsection{Thiolactoside primers}

Sulfur containing compounds have various applications in the pharmaceutical industry and in synthetic chemistry as glycosyl donors for the synthesis of complex oligisaccharides (Castaneda, 2007; Codee, 2005; Garegg, 1997; Krag, 2010; Witzak, 2005). Thiolactosides 
having a lactose moiety linked to a hydrophobic dodecyl aglycon unit via S-glycosidic bond have also been prepared and administered into mouse melanoma B16 cells (Mori et al., 2011).

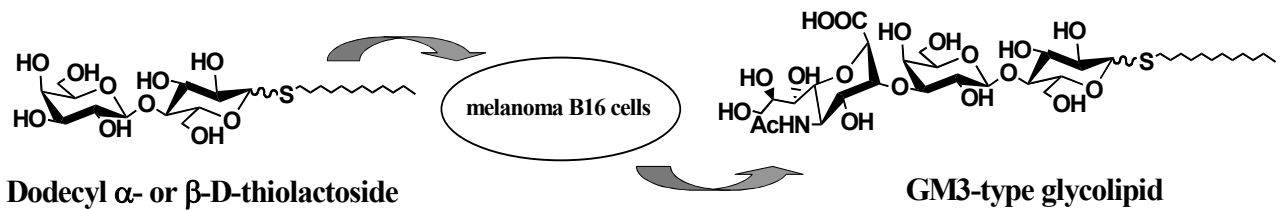

Cellular uptake of either $n$-dodecyl $\beta$-thiolactoside ( $\beta$-LacSC12) or $n$-dodecyl $\alpha$-thiolactoside ( $\alpha$-LacSC12) afforded GM3-type glycolipid. Noteworthy is that the sialyl transferases residing in the Golgi of melanoma B16 cells also recognized and elongated the primer with an S-glycoside linkage.

Interestingly, the addition of the thiolactoside primers resulted to a remarkable change on melanoma B16 cell morphology. Although B16 cells are epidermoid, cells became elongated and acquired a slender shape that is similar to fibroblast cells in the presence of thiolactoside primers (Figure 5). Significantly, increased melanin secretion was observed from B16 cells incubated in the presence of $\alpha$-LacSC12 primer as evidenced by the brown coloration of the culture medium collected. The $\alpha$-linked thiolactoside possibly inflicted stress on the melanoma B16 cells resulting to elevated production of the pigment melanin. As a natural response to stimuli, the skin produces melanin to protect from damage. Melanoma B16 cells increased production of the pigment to protect the cells from damage in the presence of the $\alpha$-linked thiolactoside. Coloration of the culture medium was observed in the following order: $\alpha$-LacSC12 > control $>\beta$-LacSC12.

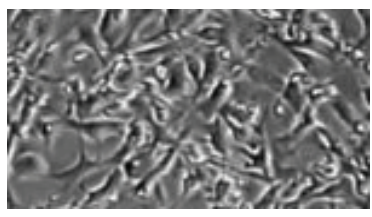

Control

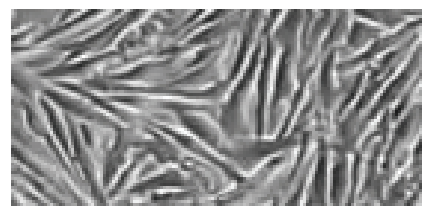

$\alpha$-LacSC12

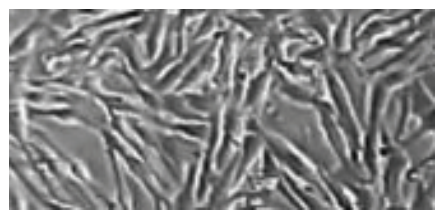

$\beta$-LacSC12

Fig. 5. Effect of thiolactoside primers on morphology of melanoma B16 cells.

\subsection{2-Azido and 12-azido dodecyl lactoside primers}

In view of the biological significance and potential application attached to the products obtained via saccharide primer method, it is essential that the saccharide primer should still be amenable to further modification after elongation. A functional group such as an azide is excellent for the preparation of glycopolymers and glycoconjugates. After internalization and glycosylation of saccharide primers by cells, the azido group at the aglycon can be selectively reduced to an amino group and conjugated for the synthesis of functional polymers.

Two types of saccharide primers, 12-azidododecyl $\beta$-lactoside and 2-azidododecyl $\beta$ lactoside were prepared and introduced to melanoma B16 cells (Kasuya, 2000; Murozuka, 2005). These primers were designed with the azido group at different positions in the 
aglycon unit to determine the effect of the position of the functional group on cellular uptake and glycolipid production.

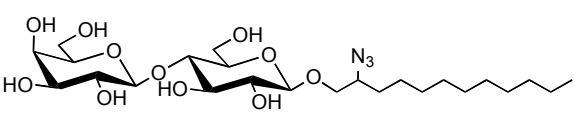

2-azidododecyl $\beta$-lactoside

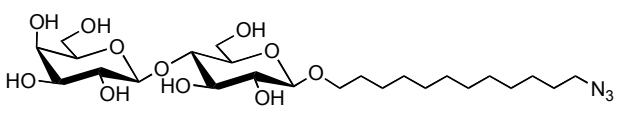

12-azidododecyl $\beta$-lactoside

Incubation with $50 \mu \mathrm{M}$ of either 12-azidododecyl $\beta$-lactoside or 2-azidododecyl $\beta$-lactoside primers has no inherent damage to cells. Expectedly, melanoma B16 cells incorporated and elongated both primers to give GM3-type oligosaccharide that was mostly secreted in the culture medium. Like the rest of the primers used, the azidododecyl lactoside primers also inhibited the synthesis of endogenous GM3. The limited amount or capability of endogenous sialyltransferases possibly accounts for the inhibition.

Although both primers could be taken up by cells and transported to the Golgi, the glycosylation site, the relative ability to pass through the membrane and be recognized as substrate for sialyl transferases is different. The 2-azidododecyl $\beta$-lactoside could pass through the plasma membrane with relative ease than 12-azidododecyl $\beta$-lactoside. Consequently, the amount of product obtained from 2 -azidododecyl $\beta$-lactoside (14\% yield) was higher than the 12 -azidododecyl $\beta$-lactoside $(7.6 \%$ yield) under the same conditions.

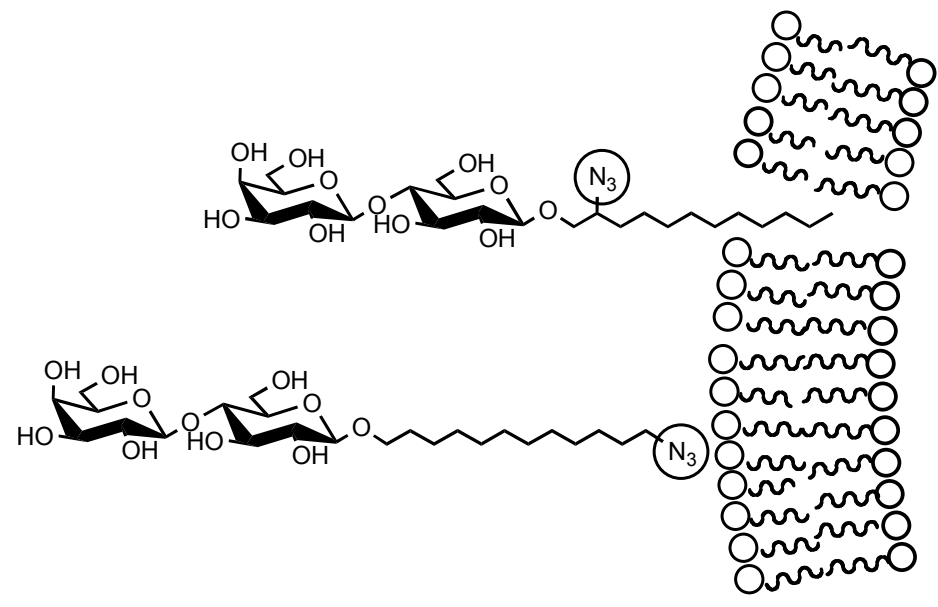

\subsection{Fluorous-tagged saccharide primers}

The interplay between the hydrophilic and hydrophobic balance brought about by the saccharide residue and the aglycon unit, respectively, is an important factor in glycolipid production using amphiphilic glycosides and melanoma B16 cells. This was demonstrated by using saccharide primers with various perfluoroalkyl aglycon units.

A series of lactosides with different perfluoroalkyl chain [LacH6F6 (each number indicates the number of $\mathrm{CH}_{2}$ and $\mathrm{CF}_{2}$, respectively), LacH2F8, LacH3F8, LacH2F10] were chemically synthesized and introduced to mouse melanoma B16 cells (Kasuya 2010a, 2010b, 2010c). After 48-h incubation, results showed that primers did not affect cell morphology and 
viability at a concentration of $50 \mu \mathrm{M}$. Moreover, the numerous fluorine atoms did not pose a steric barrier to primer assimilation into cells. The fluorous-tagged lactoside primers were sialylated to afford GM3-type glycolipid that was mostly found in the culture medium.

Although the length of the aglycon unit subscribed to the recommended chain length, dodecyl (C12), to ensure efficient uptake and release of products, the amount of glycolipids produced and the amount of fluorous-tagged saccharides remaining in the cells varied depending on hydrophobicity that is attributed mainly on the fluorine content. Increasing the fluorine content renders the fluorous-tagged saccharide primers to be more hydrophobic (Kasuya et al., 2010). As shown in figure 6, as the fluorine content of the perfluoroalkyl tail increases, the amount of lactoside primer in the cells also increases. On the other hand, an increase in the fluorine content results to a decrease in the amount of product. Lac H2F10 with the highest fluorine content gave the least amount of product. Lac H6F6 having the least number of fluorine atoms gave the highest amount among the fluorous-tagged lactoside primers. Significantly, a relatively large amount of Lac H2F10, most hydrophobic among the fluorous-tagged primers used, was found in the cell fraction. Considering the immiscibility of fluorous layer with neither an aqueous nor an organic layer, it is noteworthy that the saccharide primers with perfluoroalkyl tail have a strong affinity for the lipid-rich cell membrane.

Lac H12
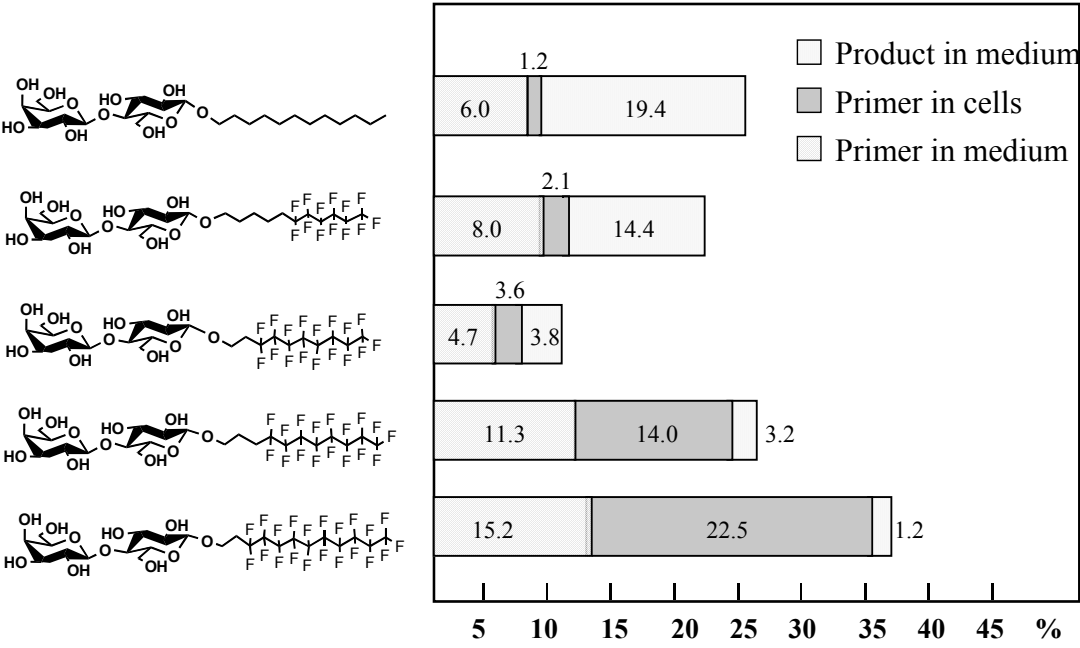

Fig. 6. Glycolipid production using saccharide primers with various perfluoroalkyl chains

\subsection{Fluorinated galactoside primers}

Ganglioside GM4 exhibits interesting biological activities. The challenging synthetic consideration that involves the regio- and stereoselective incorporation of sialic acid propelled the preparation of GM4 analogues by the saccharide primer strategy. This was achieved using dodecyl $\beta$-galactoside primer and mouse melanoma B16 cells. The replacement of a hydroxyl group by fluorine atom in the galactose residue was also pursued not only to prepare fluorinated GM4 analogues but also to establish the effect of the fluorine atom in the saccharide residue on melanoma B16 cells and glycosylation. 


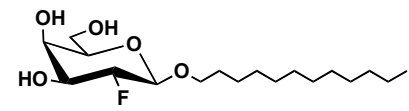

2F Gal

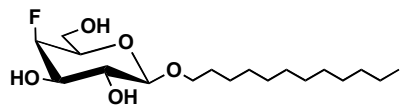

4F Gal

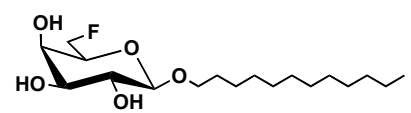

6F Gal

Fluorinated galactosides with dodecyl aglycon, 2F Gal, 4F Gal and 6F Gal, were chemically synthesized (Card \& Reddy, 1983; Dax et al., 2000) and administered to mouse melanoma B16 cells to verify their potential as scaffolds for the synthesis of a GM4 analogue (Kasuya et al., 2007). Among the 3 kinds of primers, $2 \mathrm{~F} \mathrm{Gal} \mathrm{did} \mathrm{not} \mathrm{affect} \mathrm{cell} \mathrm{morphology} \mathrm{and} \mathrm{viability.}$ In contrast, 4F Gal primer exhibited slight cytotoxicity and $6 \mathrm{~F} \mathrm{Gal}$ primer was cytotoxic at 50 $\mu \mathrm{M}$ concentration. The HPTLC results of the lipids obtained from the cell and culture medium fractions confirmed that the primers were taken-up by the cells but only the $2 \mathrm{~F} \mathrm{Gal}$ was glycosylated and the elongated product released to the culture medium. The MALDI TOF mass spectral results and treatment of the product with 2,3-sialidase (cloned from $S$. typhimurium LT2 and expressed in E. coli) confirmed the structure of the glycosylation product, a GM4 analogue.

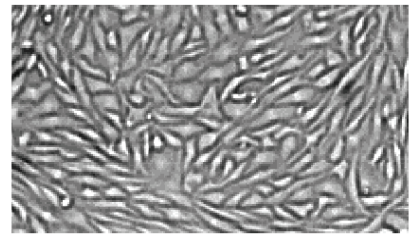

2F Gal

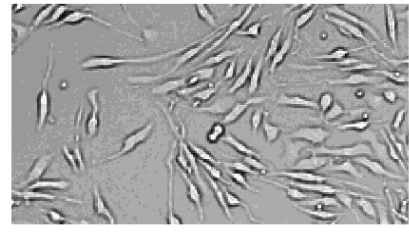

4F Gal

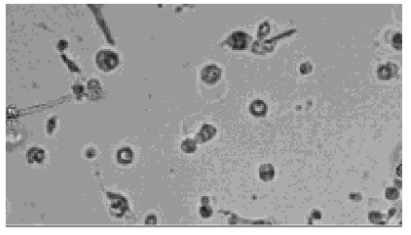

$6 \mathrm{~F} \mathrm{Gal}$

The presence of a fluorine atom was expected to have minimal effect on cell viability and primer assimilation into cells that may be attributed to the size and hydrophobicity of fluorine. However, replacement of one hydroxyl unit by a fluorine atom in different positions of the galactose residue elicited different cellular responses. A fluorine atom at 2 position of the galactose residue did not have adverse effects to the cell, and $2 \mathrm{~F}$ Gal was glycosylated. However, a fluorine atom at 4 or 6 positions slightly, or greatly, affected cell viability. As a consequence, saccharide elongation of $4 \mathrm{~F}$ and $6 \mathrm{~F}$ Gal primers did not take place. Although sialyl transferases are amenable to substrate modifications, the type and position of substituent at the vicinity of the glycosylation site (C3 position) and their positive effect on cell viability are prerequisites for cellular enzyme glycosylation and substrate recognition by 2,3-sialyl transferase.

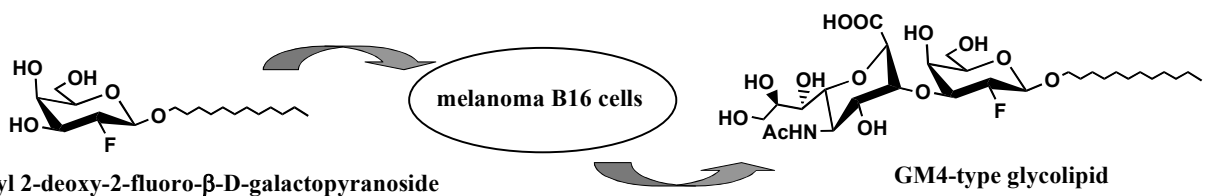

Dodecyl 2-deoxy-2-fluoro- $\beta$-D-galactopyranoside

\section{Mass production}

For the mass production of gangliosides via saccharide primer method, the choice of cell to be employed is crucial. The cells to be used should be amenable to continuous culture for 
several days that requires repeated administration of primer and harvest of culture medium. Moreover, cells should provide the desired glycolipid in fairly good yield. Mouse melanoma B16 cells meet these requirements for the production of ganglioside analogues. Other considerations for the mass production of gangliosides include optimization of seeded cell number, length of incubation time and primer concentration (Miyagawa et al., 2007).

Saccharide primers are cytotoxic when introduced to a small number of seeded cells as compared to a large number of cells due to the existence of stronger intercellular connection at the confluent state of cells. Generally, the higher the seeded cell number, the more product obtained.

The optimum length of incubation time is $48 \mathrm{~h}$. Although the amount of glycosylated product increases linearly with respect to the length of incubation time, productivity does not significantly advance beyond 48-h incubation. Moreover, long exposure to saccharide primers affects cellular morphology.

The amount of sialylated primer increases linearly with increasing concentration while consequently inhibiting endogenous GM3 production. However, beyond the optimum concentration is cytotoxic.

\subsection{GM4-type glycolipid}

The simplest among the gangliosides is sialylgalactosyl ceramide GM4 (NeuAc $\alpha 2 \rightarrow 3 \mathrm{GalCer}$ ) (Bazin, 1999; Gervay, 1993). GM4 is a minor ganglioside in human brain and has been detected in human myelin and human oligodendrocytes. However, the biological significance remains unknown. GM4 is scarce in natural sources so chemical and enzymatic synthesis remains to be the viable sources of quantitative amounts of GM4 (Otsubo, 2001; Satoh, 1996; Schnaar, 1998).

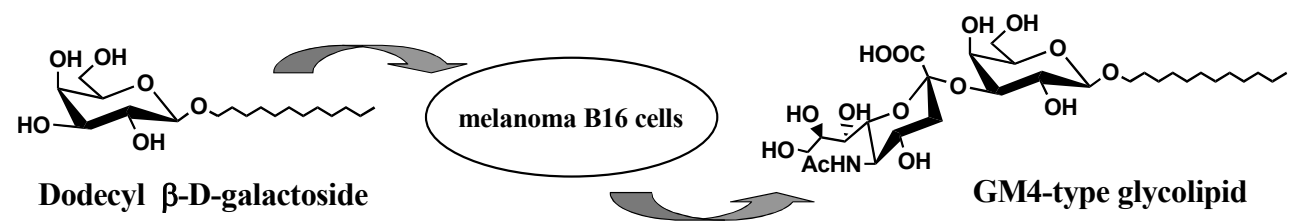

The utility of the saccharide primer method for the mass production of GM4-type ganglioside (Kasuya et al., 2010) was carried out. The optimum conditions for the mass production of GM4-type ganglioside by the saccharide primer method of employing mouse melanoma B16 cells and dodecyl $\beta$-galactoside primer (Gal C12) included: seeded cell number $\left(5 \times 10^{6}, 15 \mathrm{~cm}\right.$ dishes, $20 \mathrm{~mL}$ medium), concentration $(50 \mu \mathrm{M})$ and incubation time (48 h or $72 \mathrm{~h}$ ). Based on HPTLC results, more GM4 could be obtained from higher concentration of primer, 100 or $150 \mu \mathrm{M}$, but slight to moderate cytotoxicity was observed. Hence, $50 \mu \mathrm{M}$ was administered to cells to ensure continuous culture requiring repeated administration of primer and harvest of culture medium.

GalC12 did not exhibit adverse effects on cell morphology and viability. However, formation of colonies became evident during the second week of incubation. Cells continue to glycosylate the primer but the amount produced decreased after repeated primer administration and harvest. The culture media containing the product from all the harvests were pooled and the glycolipids were adsorbed on HP20 resin and eluted with gradient $\mathrm{MeOH}$. Purification of the products was accomplished using SepPak columns. Finally, 
purification by Centrifugal Partition Chromatography (CPC) (Kato et al., 2007) gave $4.0 \mathrm{mg}$ of the GM4 analogue with high purity from 4.2 liters of culture medium.

\section{Conclusion}

In the production of glycolipids such as GM3- and GM4-type gangliosides, melanoma B16 cells could serve as the "cell factory" that processes the saccharide primers such dodecyl $\alpha$-and $\beta$-lactoside, 2- and 12-azidododecyl lactosides, dodecyl $\beta$-galactoside, fluorinated galactoside, thiolactosides or glycosides with perfluoroalkyl chains and transforms them to GM3- and GM4-type gangliosides using endogenous enzymes and glycosyl donor. Generally, monosaccharide and disaccharide primers gave GM4- and GM3-type glycolipids, respectively.

\section{Production of GM4-type glycolipid}

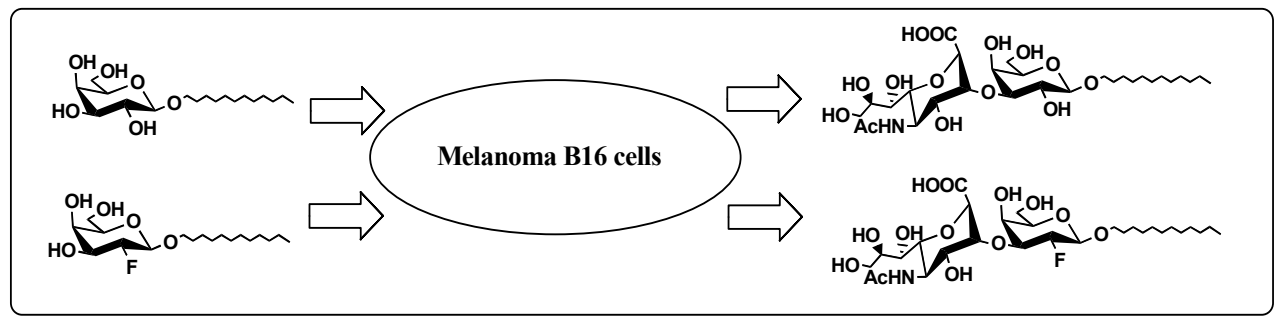

Production of GM3-type glycolipid

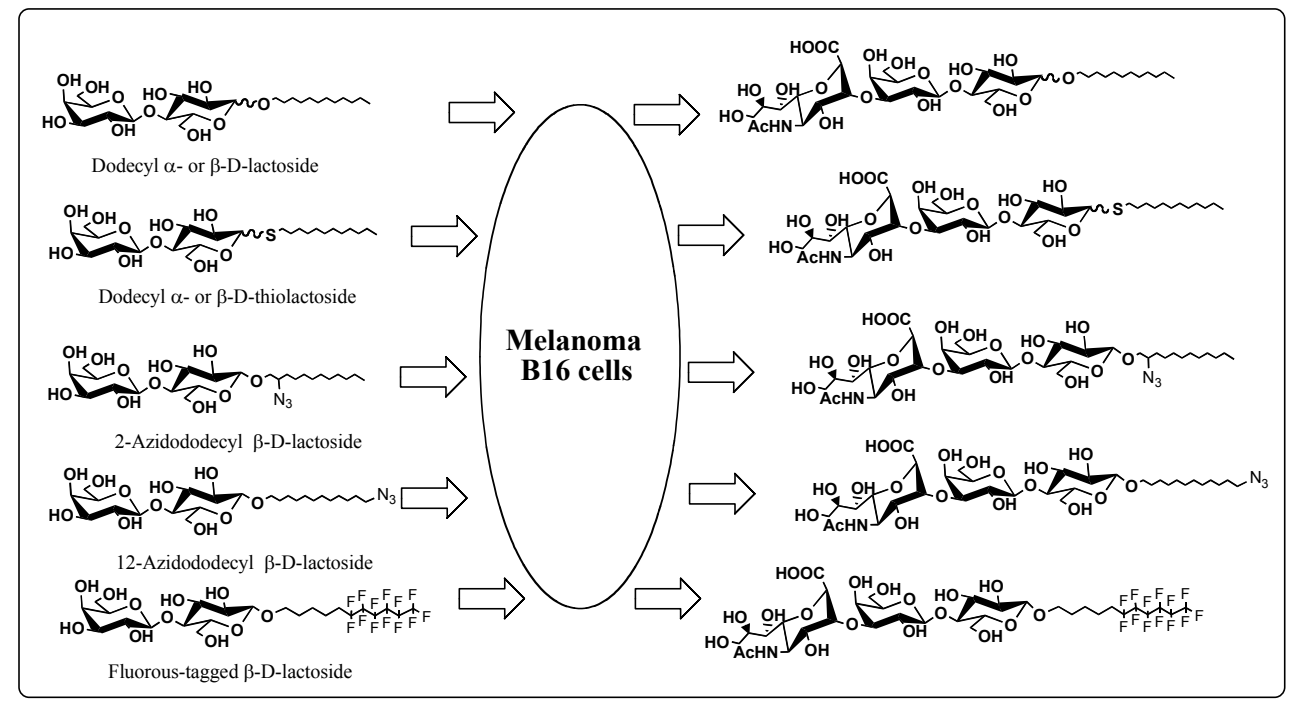

With a few exceptions, the galactoside and lactoside primers reported in this chapter (1) do not have adverse effects on morphology and viability of mouse melanoma B16 cells at 50 $\mu \mathrm{M}$ after incubation for $48 \mathrm{~h},(2)$ are taken in by melanoma B16 cells and assimilated to the Golgi, the site of glycosylation, and (3) are recognized by cellular enzymes and elongated to 
afford glycolipids that are released to the culture medium for collection, purification and identification. By employing mouse melanoma B16 cells, production of biologically important glycolipids via saccharide primer method is fast, convenient and highly stereoselective. Significantly, expensive enzymes and glycosyl donor are no longer necessary since these are endogenous to melanoma B16 cells. Melanoma B16 cells is a good candidate in the mass production of glycolipids, particularly GM3-and GM4-type gangliosides, because it is amenable to continuous culture for several days.

Depending on the type of saccharide primer and the concentration administered into melanoma B16 cells, the various effects such as elevated pigmentation, alteration of cell morphology, and decreased production of endogenous glycolipids, the saccharide primer strategy offers a fresh approach to understanding the molecular and cellular mechanism underlying the pathogenesis of melanomas. Moreover, the saccharide primer strategy could open possibilities for new therapeutic options for melanoma.

\section{Acknowledgements}

This work was supported by a grant for "Development of Novel Diagnostic and Medical Applications through Elucidation of Sugar Chain Functions" from the New Energy and Industrial Technology Development Organization (NEDO).

\section{References}

Bazin, H., Du, Y., Polat, T., Lindhart, R. (1999) Synthesis of versatile neuraminic acid "C" disaccharide precursor for the synthesis of $C$-glycoside analogues of gangliosides, Journal of Organic Chemistry, Vol.64, pp. 7254-7259.

Card, P., Reddy, G. (1983) Fluorinated carbohydrates. 2. Selective fluorination of gluco- and mannopyranosides. Use of 2-D NMR for structural assignments. Journal of Organic Chemistry, Vol.48, pp. 4734-4743.

Castaneda, F., Burse, A., Boland, W., Kinne, R. K-H. (2007) Thioglycosides as inhibitors of hSGLT1 and hSGLT2: Potential therapeutic agents for the control of hyperglycemia in diabetes, International Journal of Medical Sciences, Vol.4, pp. 131-139.

Codee, J. D., Litjens, R. E., van den Bos, L. J., Overkleeft, H. S., der Marel, G. A. (2005) Thioglycosides in sequential glycosylation strategies, Chemical Society Reviews Vol.34, No.9, pp. 769-782.

Dax, K., Albert, M., Ortner, J., Paul, B. (2000), Synthesis of deoxyfluoro sugars from carbohydrate precursors, Carbohydrate Research, Vol.327, pp. 47-86.

Freeze, H., Sampath, D., Varki, A. (1993) Alpha-and beta-xylosides alter glycolipid synthesis in human melanoma and Chinese hamster ovary cells, The Journal of Biological Chemistry Vol.268, pp. 1618-1627.

Garegg, P. J. (1997) Thioglycosides as glycosyl donors in oligosaccharide synthesis, Advances in Carbohydrate Chemistry and Biochemistry, Vol.52, pp. 179-266.

Gervay, J., Peterson, J.M., Oriyama, T., Danishefsky, S. (1993) An unexpected sialylation: Total synthesis of GM4 and a positional Isomer, Journal of Organic Chemistry, Vol.58, pp. 5465-5468.

Hakomori, S. (1981) Glycosphingolipids in cellular interaction, differentiation, and oncogenesis. Annual Reviews in Biochemistry, pp. 733-764.

Hoon, DS., Irie, RF., Cochran, AJ., (1988) Gangliosides from human melanoma immonomodulate response of T cells to interleukin-2. Cell Immunology, Vol.111, No.2, pp. 410-419. 
Hoon DS., Kaback, MM., Lim-Steele, J., Tsuchida. T., Morton, DL., Irie, RF. (1992) Ganglioside GN2 levels in human melanoma cells: inverse correlation with lysosomal beta-hexosaminidase A activity. Biochemistry International. Vol.27, No.2, pp. 343-352.

Kasuya, M.C.Z., Wang, L.; Lee, Y.C.; Mitsuki, M.; Nakajima, N.; Sato, T.; Hatanaka, K.; Yamagata, S.; Yamagata, T. (2000) Azido glycoside primer: a versatile building block for the biocombinatorial synthesis of glycosphingolipid analogues. Carbohydrate Research, Vol. 329, pp. 755-763.

Kasuya, M.C.Z.; Cusi, R.; Ishihara, O.; Miyagawa, A.; Hashimoto, K.; Sato, T.; Hatanaka, K. (2004) Fluorous-tagged compound: a viable scaffold to prime oligosaccharide synthesis by cellular enzymes. Biochemical Biophysical Research Commununications, Vol.316, No.3, pp. 599-604.

Kasuya, M.C.Z., Ikeda, M., Hashimoto, K., Hatanaka, K. (2005) Effect of anomeric linkage on the sialylation of glycosides by cells, Journal of Carbohydrate Chemistry, Vol.24, pp. 705-715.

Kasuya, M.C.Z.; Hatanaka, K. (2010) Production of GM4 analogue using animal cells in culture, Chemistry and Biodiversity, Vol.7, No.2, pp 440-446.

Kasuya, M.C.Z.; Tojino, M.; Mizuno, M.; Hatanaka, K.; (2010) Effect of fluorous tags on glycosylation of saccharide primers in animal cells, Bulletin of the Chemical Society of Japan, Vol.82, No.11, pp 1409-1415.

Kasuya, M.C.Z., Tojino, M., Mizuno, M., Hatanaka, K. (2010) Fluorous tag method for the simultaneous synthesis of different kinds of glycolipids, Journal of Fluorine Chemistry, Vol.131, pp.655-659.

Kasuya, M.C.Z., Nakano. S., Katayama, R., Hatanaka, K. (2010) Evaluation of the hydrophobicity of perfluoroalkyl chains in amphiphilic compounds that are incorporated into cell membrane, Journal of Fluorine Chemistry, Vol.131, pp.655-659.

Kasuya, M.C.Z., Ito, A., Hatanaka, K. (2007) Simple and Convenient Synthesis of a Fluorinated GM4 Analogue, Journal of Fluorine Chemistry, Vol.128, pp. 562-565.

Kato, T., Miyagawa, A., Kasuya, M.C.Z., Ito, A., Hatanaka, K. (2007) Purification by centrifugal partition chromatography of amphiphilic compounds, glycolipids and pseudo-glycolipids synthesized by using cells, Journal of Chromatography, Vol.178, pp. 154-159.

Kolter, T., R. Proia, K. Sandhoff. (2002) Combinatorial Ganglioside Biosynthesis, Journal of Biological Chemistry, Vol.277, pp 25859-25862.

Krag, J., Christiansen, M. S., Petersen, J. G., Jensen, H. H. (2010) Direct chemical glycosylation with pentenyl- and thioglycoside donors of N-acetylglucosamine, Carbohydrate Research, Vol.345, No.7, pp. 872-879.

Li, Y-T., Sugiyama, E., Ariga, T., Nakayama, J., Hayama, M., . Hama, Y., Nakagawa, H., Tai, T., Maskos, K., Li, S-C., Ksama, T. (2002) Association of GM4 ganglioside with the membrane surrounding lipid droplets in shark liver, Journal of Lipid Research, Vol.43, pp.1019-1025.

Miura, Y., Yamagata, T. (1997) Glycosylation of lactosylceramide analogs in animal cells: amphiphatic disaccharides primers for glycosphingolipid synthesis, Biochemical and Biophysical Research Communications, Vol.241, pp. 698-703.

Miyagawa, A., Kasuya, M.C.Z., Hatanaka. K. (2007) Alternative methods of globotrioside production using Vero cells: a microcarrier system procedure, Chemistry Central Journal, Vol.1, pp 26. 
Mori, M.; Kasuya, M.C.Z., Mizuno, M., Hatanaka, K. (2011) Thiolactosides: Scaffolds for the synthesis of glycolipids in animal cells, International Journal of Carbohyrate Chemistry. In press.

Murozuka, Y., Kasuya, M.C.Z., Kobayashi, M., Watanabe, Y., Sato, T., Hatanaka, K. (2005) Efficient sialylation on azidododecyl lactosides by using B16 melanoma cells, Chemistry and Biodiversity, Vol.2, pp 1063-1078.

Nakajima, H., Miura, Y., Yamagata, T. (1998) Glycosylation of amphiphatic lactoside primers with consequent inhibition of endogenous glycosphingolipid synthesis, Journal of Biochemistry, Vol.124, pp. 148-156.

Otsubo, N., Ishida, H., Kiso., M., (2001) Synthesis of novel ganglioside GM4 analogues containing $\mathrm{N}$ - deacetylated and lactamized sialic acid: probes for searching new ligand structures for human L-selectin, Journal of Carbohydrate Research, Vol.330, pp 1-5.

Ozawa, H., Kotani, M., Kawashima, I., (1993) Generation of a monoclonal antibody specific for ganglioside GM4: Evidence for GM4 expression on astrocytes in chicken cerebellum, Journal of Biochemistry, Vol.114, pp. 5-8.

Pritchett, T.; Paulson, J. (1989) Basis for the potent inhibition of influenza virus infection by equine and guinea pig 2-macroglobulin, Journal of Biological Chemistry, Vol.264, No.17, pp. 9850-9858.

Saito, M., Rosenberg, A. (1982) Sialosylgalactosylceramide (GM4) is a major ganglioside in chicken embryonic liver. Journal of Lipid Research, Vol.23, pp.9-13.

Sarkar, A., Brown, J., Esko, J. (2000) Synthesis and glycan priming activity of acetylated disaccharides, Carbohydrate Research, Vol.329, pp. 287-300.

Sarkar, A., Rostand, S., Jain, R., Matta, K., Esko, J. (1997) Fucosylation of disaccharide precursors of sialyl LewisX inhibit selectin-mediated cell adhesion, The Journal of Biological Chemistry, Vol.272, pp. 25608-25616.

Sarkar, A., Fritz, T., Taylor, W., Esko, J. (1995) Disaccharide uptake and priming in animal cells: Inhibition of sialyl Lewis $X$ by acetylated Gal $\beta 1 \rightarrow 4$ GlcNAc $\beta-O-$ naphthalenemethanol, Proceedings of the National Academy of Sciences of the United States of America, Vol.92, pp. 3323-3327.

Sato, T., Hatanaka, K., Hashimoto, H., Yamagata, T. (2007) Synthesis of oligosaccharides using cell function, Trends in Glycoscience and Glycotechnology, Vol.19 pp.1-17.

Satoh, J., Tai, T., Kim, S.U. (1996) Differential expression of gangliosides and galactolipids in fetal human oligodendrocytes and astrocytes in culture, Brain Research Development, Vol.93, pp. 172-81.

Schnaar, R., Collins, B., Wright, L., Kiso, M., Tropak, M., Roder, J. Crocker, P. (1998.) Myelin Nassociated glycoprotein binding to gangliosides: Structural specificity and functional implications. Annals of the New York Academy of Science, Vol.845, pp 92-105

Sun, X.-L.; Kanie, Y.; Guo, C.-H.; Kanie, O.; Suzuki, Y.; Wong, C.-H. (2000) Synthesis of C-3 modified sialylglycosides as selective inhibitors of influenza hemagglutinin and neuraminidase. European Journal of Organic Chemistry, pp 2643-2653.

Suzuki, Y., Sato, K., Kiso, M., Hasegawa, A. (1990) New ganglioside analogs that inhibit influenza virus sialidase, Glycoconjugate Journal, Vol.7, pp. 349-356.

Svennerholm, L. (1957) A colorimetric resorcinol - hydrochloric acid method, Biochimica et Biophysica Acta, Vol.24, pp. 604-611.

Varki, A.; Cummings, R.; Esko, J.D.; Freeze, H.H.; Hart, G.; Marth, J. (1999) Essentials of Glycobiology, Cold Spring Harbor Laboratory Press, New York.

Witzak, Z. J., Culhane, J.M. (2005) Thiosugars: new perspectives regarding availability and potential biochemical and medicinal applications, Applied Microbiology and Biotechnology, Vol.69, No.3, pp. 237-244. 


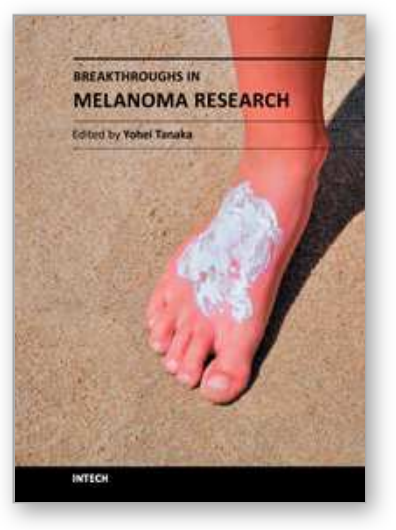

\author{
Breakthroughs in Melanoma Research \\ Edited by Dr Yohei Tanaka
}

ISBN 978-953-307-291-3

Hard cover, 628 pages

Publisher InTech

Published online 30, June, 2011

Published in print edition June, 2011

Melanoma is considered to be one of the most aggressive forms of skin neoplasms. Despite aggressive researches towards finding treatments, no effective therapy exists to inhibit the metastatic spread of malignant melanoma. The 5-year survival rate of metastatic melanoma is still significantly low, and there has been an earnest need to develop more effective therapies with greater anti-melanoma activity. Through the accomplishment of over 100 distinguished and respected researchers from 19 different countries, this book covers a wide range of aspects from various standpoints and issues related to melanoma. These include the biology of melanoma, pigmentations, pathways, receptors and diagnosis, and the latest treatments and therapies to make potential new therapies. Not only will this be beneficial for readers, but it will also contribute to scientists making further breakthroughs in melanoma research.

\title{
How to reference
}

In order to correctly reference this scholarly work, feel free to copy and paste the following:

Maria Carmelita Z. Kasuya and Kenichi Hatanaka (2011). Melanoma Cell Factory for Glycolipid Production, Breakthroughs in Melanoma Research, Dr Yohei Tanaka (Ed.), ISBN: 978-953-307-291-3, InTech, Available from: http://www.intechopen.com/books/breakthroughs-in-melanoma-research/melanoma-cell-factory-forglycolipid-production

\section{INTECH}

open science | open minds

\author{
InTech Europe \\ University Campus STeP Ri \\ Slavka Krautzeka 83/A \\ 51000 Rijeka, Croatia \\ Phone: +385 (51) 770447 \\ Fax: +385 (51) 686166 \\ www.intechopen.com
}

\author{
InTech China \\ Unit 405, Office Block, Hotel Equatorial Shanghai \\ No.65, Yan An Road (West), Shanghai, 200040, China \\ 中国上海市延安西路65号上海国际贵都大饭店办公楼405单元 \\ Phone: +86-21-62489820 \\ Fax: +86-21-62489821
}


(C) 2011 The Author(s). Licensee IntechOpen. This is an open access article distributed under the terms of the Creative Commons Attribution 3.0 License, which permits unrestricted use, distribution, and reproduction in any medium, provided the original work is properly cited. 